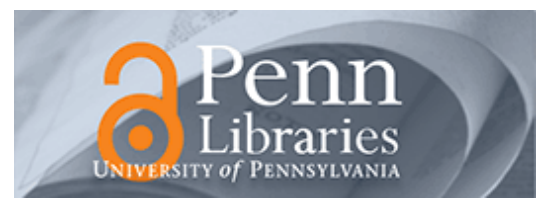

University of Pennsylvania

ScholarlyCommons

\title{
$5-2011$
}

\section{A Qualitative Meta-Analysis of Heart Failure Self-Care Practices among Individuals with Multiple Comorbid Conditions}

Victoria V. Dickson

University of Pennsylvania

Harleah G. Buck

Barbara Riegel

University of Pennsylvania, briegel@nursing.upenn.edu

Follow this and additional works at: https://repository.upenn.edu/nrs

Part of the Behavioral Medicine Commons, Cardiology Commons, Cardiovascular Diseases Commons, Circulatory and Respiratory Physiology Commons, Medical Humanities Commons, and the Nursing Commons

\section{Recommended Citation}

Dickson, V. V., Buck, H. G., \& Riegel, B. (2011). A Qualitative Meta-Analysis of Heart Failure Self-Care Practices among Individuals with Multiple Comorbid Conditions. Journal of Cardiac Failure, 17 (5), 413-419. http://dx.doi.org/10.1016/j.cardfail.2010.11.011

This paper is posted at ScholarlyCommons. https://repository.upenn.edu/nrs/159

For more information, please contact repository@pobox.upenn.edu. 


\title{
A Qualitative Meta-Analysis of Heart Failure Self-Care Practices among Individuals with Multiple Comorbid Conditions
}

\begin{abstract}
Background

Most heart failure (HF) patients have other comorbid conditions. HF self-care requires medication and diet adherence, daily weight monitoring, and a thoughtful response to symptoms when they occur. Selfcare is complicated when other chronic conditions have additional self-care requirements. The purpose of this study is to explore how comorbidity influences HF self-care.

Methods

Using qualitative descriptive meta-analysis techniques, transcripts from 3 mixed methods studies $(n=99)$ were reexamined to yield themes about perceptions about $\mathrm{HF}$ and self-care and to explore the influence on HF self-care. The Charlson Comorbidity Index identified comorbid conditions.

Results

The sample was $74 \%$ Caucasian, $66 \%$ male (mean age of 59.6 years \pm 15 years). Fifty-three percent of the sample was New York Heart Association Class III. All had at least 1 other chronic condition. Narrative accounts revealed that adherence to diet, symptom monitoring, and differentiating symptoms from multiple conditions were the most challenging self-care skills. Emerging themes included 1) attitudes drive self-care prioritization and 2) fragmented self-care instruction leads to poor self-care integration and self-care skill deficits.

\section{Conclusions}

Individuals with multiple chronic conditions are vulnerable to poor self-care. Research testing coaching interventions that integrate self-care requirements and focus on developing skill in self-care across multiple chronic conditions is needed.
\end{abstract}

\section{Keywords}

self-care, heart failure, comorbidity

\section{Disciplines}

Behavioral Medicine | Cardiology | Cardiovascular Diseases | Circulatory and Respiratory Physiology | Medical Humanities | Medicine and Health Sciences | Nursing 
A Qualitative Meta-Synthesis of Intentional and Unintentional Medication Nonadherence in Adults with Chronic Heart Failure

\author{
Barbara Riegel, PhD, RN, FAHA, FAAN \\ Edith Clemmer Steinbright Professor of Gerontology \\ University of Pennsylvania School of Nursing \\ Victoria Vaughan Dickson, PhD, RN, FAHA, FAAN \\ Associate Professor \\ New York University College of Nursing
}

\title{
Corresponding Author:
}

Barbara Riegel, PhD, RN, FAHA, FAAN

Edith Clemmer Steinbright Professor of Gerontology

University of Pennsylvania School of Nursing

418 Curie Boulevard

Philadelphia, PA 19104-4217

215-898-9927 (W)

240-282-7707 (eFAX)

briegel@nursing.upenn.edu

Key words: medication adherence, self-care, common sense model, heart failure 


\begin{abstract}
$\underline{\text { Abstract }}$
Objective: To explore factors contributing to intentional and unintentional medication nonadherence in adults with chronic heart failure (HF).

Background: Medication nonadherence is prevalent in HF but the factors contributing to it are not well understood.

Methods: This secondary data analysis of qualitative data explored narrative accounts about medication adherence from four previous studies $(\mathrm{N}=112)$. The Necessity-Concerns-Framework derived from the Common Sense Model (CSM) of Self-Regulation guided the interpretation of themes.

Results: In this diverse sample (39\% Black, 6\% Hispanic, 63\% male; mean age $59 \pm 15$ years), $90 \%$ reported at least intermittent nonadherence. For many $(60 \%)$, missing medication was unintentional but $27 \%$ reported intentional nonadherence. Four interconnected patterns of behavior emerged: 1) rarely nonadherent, 2) frequently nonadherent, 3) intentionally nonadherent, and 4) reformed nonadherent. Misperceptions about HF, beliefs, concerns, and contextual factors contributed to both intentional and unintentional nonadherence.

Conclusion: Medication nonadherence is prevalent in HF and influenced by modifiable factors.
\end{abstract}

Key words: medication adherence, self-care, common sense model, heart failure Abbreviations list:

- HF, heart failure

- CSM, Common Sense Model

- NYHA, New York Heart Association 


\section{$\underline{\text { Introduction }}$}

Medications are the single most important factor in slowing, arresting, and occasionally reversing chronic heart failure (HF). Yet, medication adherence is poor in adults with HF. These patients take, on average, 10 different medications daily, most with multiple doses required. Even among those with drug coverage insurance benefits, $40-60 \%$ adhere poorly to the prescribed regimen. ${ }^{1}$ Over time, full adherence to the regimen may be as low as $10 \%{ }^{2}$

Medication adherence is defined as the extent to which medications are taken as prescribed. ${ }^{3}$ Both intentional and unintentional factors contribute to nonadherence. Intentional nonadherence is deliberate discontinuing, skipping or reducing the dose of medication. ${ }^{4,5}$ Factors known to contribute to such decisions include poor motivation, adverse side effects, perceived lack of effect, regimen complexity, being asymptomatic, individual perceptions (e.g., think the medicine is unnecessary) and poor health literacy. ${ }^{6,7}$ Unintentional nonadherence is careless missing of doses or errors due to factors such as forgetfulness and poor understanding of the prescribed instructions that is largely driven by a lack of capacity or resources to take medications. ${ }^{6}$ The reasons underlying intentional and unintentional nonadherence may not be entirely independent in that certain types of unintentional nonadherence (e.g. forgetting) are logically more likely when patients are not motivated to take a medicine. ${ }^{6}$

Medication nonadherence is known to be common in $\mathrm{HF}^{8}$ and nonadherence is strongly associated with HF outcomes. ${ }^{9,}{ }^{10}$ However, we know surprisingly little about the reasons for nonadherence in HF patients. In other populations, reasons for nonadherence are known to vary for different medications and different illnesses, ${ }^{11-13}$ which highlights the importance of investigating nonadherence in subgroups of patients. Unintentional nonadherence is thought to be more common than intentional nonadherence, ${ }^{14}$ but these dimensions of nonadherence have 
not been described in HF patients. Understanding the prevalence of and reasons for intentional and unintentional nonadherence can potentially contribute in important ways to the design of effective behavioral interventions to improve medication adherence. ${ }^{15,16}$ Thus, the objective of this study was to explore factors contributing to intentional and unintentional medication nonadherence in a sample of adults with chronic HF.

\section{Theoretical Framework}

The Common Sense Model (CSM) of Illness Representation was developed as a way of conceptualizing poor patient adherence with health-promoting behaviors. ${ }^{17,18}$ The CSM posits that illness perceptions (the illness label or diagnosis and associated symptoms), causes, timeline (acute, chronic or cyclical), consequences (social, monetary and health-related consequences of the illness and treatment) and control beliefs (the degree of control the patient thinks s/he has, the doctor has and the treatment has) affect behavior. ${ }^{17,}{ }^{19}$ Building on the CSM, Horne ${ }^{5}$ developed the Necessity-Concerns-Framework (Figure), which specifies that medication adherence is a function an individual's illness beliefs. Illness beliefs lead to concerns and questions about whether a drug is really necessary, which may cause intentional nonadherence. A significant proportion of individuals are concerned that medicines are harmful, unnatural, and better avoided. ${ }^{20}$ Horne notes that "unintentional nonadherence may be understood in terms of skills and abilities, whereas to understand intentional nonadherence we must consider patients' motivation to initiate and persist with the treatment regimen"5 (p.67S). These elements of the Necessity-Concerns-Framework were used to explore intentional and unintentional factors contributing to medication nonadherence in adults with chronic HF.

\section{$\underline{\text { Methods }}$}

This was a secondary analysis of qualitative data from four studies in the investigators' programs 
of HF self-care research. Secondary data analysis of qualitative data is a research strategy that makes use of existing qualitative data for the purposes of investigating new questions ${ }^{21}$ or applying a new perspective or conceptual focus to the existing research. ${ }^{22}$ There are numerous advantages to secondary data analysis of qualitative datasets ${ }^{21}$ including the ability to generate new knowledge or new hypotheses, or support existing theories while reducing human subject burden. Secondary data analysis of qualitative data also allows wider use of data from typically underrepresented research subjects. ${ }^{23}$

A key premise of secondary data analysis is that there is a fit between the primary data sets and the new research question that includes similar data collection and analytic techniques. ${ }^{23,24}$ In selecting datasets to include in a secondary data analysis, assessment of dataset quality, including depth or richness of data, is important to achieve answers to the proposed research question. ${ }^{22}$ In this secondary analysis, qualitative data from four completed studies were analyzed, all of which explored biobehavioral and sociocultural influences on self-care or tested an intervention to improve self-care. A sample of 125 individuals participated in one of the four prior studies; medication adherence was discussed by 112 of these participants (Table 1). The qualitative component of each prior study had been led by one of these authors (VVD), an experienced, highly trained qualitative methodologist. This investigator either personally interviewed participants or personally trained interviewers to collect the qualitative data. Each study complied with the Declaration of Helsinki, locally appointed ethics committees approved the research protocols, and informed consent was obtained from all participants.

Each study used a series of similar open-ended questions ("Tell me about your heart failure" and "What do you do on a daily basis to take care of your heart failure?") to elicit in-depth accounts of self-care. To gain insight into medication adherence, an essential component of HF self-care, 
focused questions about medication taking were asked ("Tell me about your medication"). Nonadherence was defined liberally in this qualitative analysis as skipping medication doses or reducing doses taken on an intermittent or frequent basis, regardless of cause. A liberal definition was used because no objective measure of medication taking behavior was available. Thus, medication adherence was judged based on patient statements. Barriers and facilitators to medication adherence were elicited through a series of follow-up probes asking about caregiver support for adherence and perceptions about importance of medication taking. Thus data collection and analytic techniques across studies were assured; and in-depth narratives about medication adherence provided for a rich qualitative dataset for this secondary analysis.

\section{Qualitative Data Analysis}

The qualitative data from these four studies were analyzed in a systematic manner using thematic content analysis. $^{25,26}$ The steps of analysis are detailed in Table 2. This process yielded a rich description and over 400 coded data segments about medication adherence. Individual findings were first reviewed first at the level of codes, focusing on the categories and themes originally coded as related to the medication adherence. Qualitative data were re-examined and re-coded by a single investigator (VVD) as reports of intentional and unintentional medication nonadherence. Next, qualitative accounts of medication nonadherence were explored and organized within the theoretical context of the Necessity-Concerns-Framework. Finally, the pattern of themes was reviewed across studies. This within-study and across-study analysis was an iterative process involving a reanalysis of the original raw data and a reinterpretation of previous findings to answer additional questions about intentional and unintentional contributors to medication nonadherence.

Methodological rigor of the qualitative analysis was maintained through an audit trail, periodic 
debriefing with the co-investigator and discussions with colleagues knowledgeable about HF, medication adherence, and the Necessity-Concerns-Framework. Reliability was measured by consistency of interpretation and coding. ${ }^{27}$ An audit trail of process and analytic memos and coding books was maintained to support the credibility of the study.

$\underline{\text { Results }}$

Sample demographic and clinical characteristics are shown in Table 3. The final sample consisted of 112 participants; 41 (37\%) were women. Ages ranged from 25 to 98 years (mean age $59 \pm 15$ years) with almost half (46\%) older than 60 years. Most (58\%) participants were White and most had New York Heart Association (NYHA) class II (41\%) or class III (55\%) HF. In this sample, $90 \%$ admitted to some amount of medication nonadherence. For many (60\%), missing medication was unintentional and most commonly due to forgetfulness but $27 \%$ ( $\mathrm{n}=30$ ) admitted to intentionally skipping medication doses. Distinct patterns of behavior were evident.

\section{Illness Perceptions and Perceived Need}

Participants discussed experiencing typical HF symptoms including weight gain (43\%), ankle swelling (50\%), shortness of breath (54\%), and fatigue (74\%), but they did not always interpret these symptoms as related to HF. Symptom interpretation was based on prior experience and the severity of symptoms. For example, most recognized symptoms like weight gain, ankle swelling and breathing problems as related to fluid retention and linked to HF ("I get short of breath, I know the fluid is backing up in the lungs and I could end up in the hospital again."). Episodic weight gains and ankle edema, which signaled fluid retention, prompted the need to take an extra diuretic. Interpretation of symptoms as HF-related reinforced the importance of routinely taking medication. As one 42 year old White woman explained, "I feel better when I take my medicines...my ankles don't swell, I don't retain fluid...so I ALWAYS take my medication." Similarly, several described how the acute onset of symptoms like shortness of breath or chest 
pain signaled worsening $\mathrm{HF}$ and prompted medication taking to alleviate the symptom.

Fatigue and lack of energy, although mentioned by $74 \%$ of participants, were less often interpreted as HF-related. Many in this sample reported having a chronic, vague symptom like feeling tired, which they "have to get used to" rather than a symptom that can be managed with medication. Thus, the importance of medication to the management of these symptoms was rarely mentioned. In a very few cases $(n=5)$, vague symptoms were recognized as representing HF and alleviated by medications; these patients knew that taking medication regularly was important. A 45 year old White male described the importance of his medication as, "My heart failure symptom is fatigue...probably the primary...I take my medication and I feel better...more energy..." These results suggest that symptom recognition and interpretation influence the perception of $\mathrm{HF}$ as a serious illness requiring medications.

Situational nonadherence was most frequently described by those who perceived HF as a low threat condition. In these cases, deliberate cognitive ("one day I forgot and there was no difference in how I felt...") and emotional ("...so if I am going to be out with my friends...I don't want to carry the pillbox...") processes were described as influencing actions. The pros and cons of taking medication were appraised, providing a rationale to the decision to purposively "skip medication". Certain situations like travel, vacation, work or family events outweighed the perceived need for medication.

\section{$\underline{\text { Background Beliefs }}$}

When HF was perceived as inconsequential, negative attitudes regarding the importance of the medication regimen influenced adherence. Those who believed that the medication was either not helpful ("I was taking all these...10 pills ... for years. In my opinion, they were not doing 
anything...so I stopped taking them...") or in conflict with their personal preferences ("I have always hated taking pills...so I skip them some days...") questioned necessity and purposively missed doses.

A subset described intentional nonadherence as a means of regaining control over their life and illness. In these narratives, loss of personal control was described. As one 51 year old Black male described, “...sometimes I don't take all of them...I used to be very active so if I take them I can't do what I want... sometimes, I just want to feel like myself again...I want to feel normal."

\section{$\underline{\text { Concerns }}$}

Complex regimens highlighted concerns about potential dangers. Many of these participants had multiple conditions and complex regimens ("I think it is too much... I think $<H F$ medication $>$ makes the sugar low and when the sugar's low...that I know is very bad"). As a result, some reported only taking the medications they perceived as most necessary.

Other concerns were linked to past experiences. Undesirable side effects of HF medications were reported by 17 (15\%) individuals and these negative past experiences ("...I don't want to end up having that problem again on the plane...”) outweighed perceived benefits of medication. In addition, lack of knowledge about how to manage a missed dose generated concerns about potential dangers ("When I remember it, I worry about what to do... will it be like a double dose if I take it too late...”). Those without strategies to deal with such situations were vulnerable to medication nonadherence.

Concerns about physical and mental wellbeing resulted in unintentional nonadherence for some. Sleeping too much and feeling fatigued resulted in missed doses ("I slept too long and missed the 
time for my pills"). Being depressed resulted in missed doses because of feeling unable to execute the behavior. One 74 year old White woman described that she always takes her medication with food so when she does not "feel strong enough to cook", she may wait to take her medication "until I feel better".

\section{$\underline{\text { Contextual Issues }}$}

A variety of contextual issues influenced adherence in positive and negative ways. Instructions from healthcare providers about symptoms $("<$ doctor $>$ told me to watch and if I get short of breath...") and social supporters/caregivers ("<wife $>$ knows before I do that $<H F>$ is worse”) helped patients recognize and interpret their symptoms as HF-related. Cues such as pill boxes or calendars noting medication schedules helped them incorporate pill taking into their daily routines ("the pill box is by the coffee...for years I have been getting my cup of coffee...now I take my pills and get my coffee...). Other contextual cues included reminders from caregivers ("wife's the boss...she puts the pills in my hands and makes sure I take them ALL...) or the healthcare system (e.g., automatic pharmacy renewals). These environmental stimuli supported the perception of HF as a threat ("It's not hard to take those pills each morning...I chose to live") but one that is controllable ("this cocktail of pills that I am on is the best there is for my condition"). However, when there was an unplanned break in the daily routine ("we had visitors so I put the pillbox away...”), a gap in support (e.g., a family member not being available to refill the pill box), or an event (e.g., vacation, travel) that altered schedules, medication doses were more likely to be missed.

Fragmented care emerged as an important contributor affecting patients' adherence. For example, when a healthcare provider failed to refill a prescription after a hospitalization or gave conflicting prescriptive information, medication doses were missed. One 65 year old Black male 
described his concern over missing his diuretic since a recent hospitalization... ( “...this doctor here missed it...I know I was on a water pill because I noticed before I was passing water more than what I am now...I think I should be on it...but they missed it...”). For some, inadequate financial resources such as lack of insurance or pharmacy access made it difficult to obtain medication ("there's no pharmacy here that takes my Medicaid, so they tell me to go to $<$ pharmacy chain $>$. There's no <pharmacy chain > in my neighborhood...") or required that choices be made about which medication to take ("...If they cost too much...I don't take them ...I can't').

\section{$\underline{\text { Patterns of Medication Nonadherence }}$}

Four patterns of nonadherence emerged that help explain the complexity of medication adherence and provide important implications for intervention. Guided by the CSM, these four patterns elucidate the relative contribution of illness perceptions, beliefs, concerns, and contextual issues on the outcome of medication nonadherence.

\section{Rarely Nonadherent}

Twenty-five (22\%) individuals described being adherent most of the time and missing medication only on rare occasions. These participants had no pattern of recurrent nonadherence or intentionally skipping medications. Their representation of HF was as an illness that was "lifethreatening" but controllable with medication. Most of these reported adequate access to healthcare services and providers who had educated them about their medicines, including how to manage a missed dose. As a result, they had structured routines in place to consistently adhere to even complex regimens and systems for managing missed doses when they occurred. They described routines and cues to help them remember medicines and had positive attitudes about the importance of their medicines. 


\section{Frequently Nonadherent}

The second pattern was frequent nonadherence, but this nonadherence was unintentional. These participants $(n=57,51 \%)$ reported recurrent or routine nonadherence or patterns of nonadherence that could be linked to a situation or event (e.g., running out of medication). These situations caused them to forget on a regular basis. Although they described HF as a serious threat and noted the importance of medication, they routinely forgot to take doses and did not have effective cues or supports in place to facilitate adherence. Nor did they know how to manage missed doses. They described complicated regimens and other chronic conditions that made coping difficult. Importantly, they realized that their nonadherence was having negative health effects. They wanted to be better at taking medicines but did not have adequate knowledge or effective support in place to help them do so.

\section{Intentionally Nonadherent}

Twenty-one (19\%) individuals described that they were intentionally nonadherent on a regular basis. They described purposively skipping medication and were likely to continue to do so. They perceived HF as either low threat or they had negative attitudes about medication necessity. They described a dislike of medication taking, medication side effects, or past negative experiences with side effects that influenced their behavior. Interestingly, medication adherence was described as an act of personal choice, and for some, a means of regaining personal control. Nonadherence was situational and varied based on the day's events (work, vacation) and personal preferences (e.g., "If I just don't feel like taking <pill> today...I don't”). Further, they appraised their action of nonadherence as successful. One woman described that her husband, a 71 year old White patient with $\mathrm{HF}$, "has this idea that he does not need to take his medicine every day”. The husband explained, “...when I skip them...I don't feel differently...so I don't think I need them". 


\section{Reformed Nonadherent}

Nine individuals $(8 \%)$ reported past nonadherence that was intentional and driven by negative attitudes and an attribution of low perceived threat of HF. However, a negative experience ("I was near death") reframed their HF illness perceptions and reinforced the importance of medication. In these cases, intentional nonadherence was appraised as unsuccessful, which prompted a change in action. Through education and communication by healthcare providers ("... $<$ doctor $>$ said straighten up ...you are going to die from this....") and the adoption of strategies to reinforce adherence, they described a new commitment to taking medication " as $I$ am supposed to do not whether I want to or not". Ongoing appraisal of success reinforced the importance of medication adherence. As a 57 year old Hispanic woman described, “...that was the scariest day because I decided that I had nothing wrong with me and I had stopped taking all of the medications.... I ended up here and I was real bad... I learned that it's (sic HF) gonna be with me for a long time...I learned that I have to take my medication...so I do now and I haven't been back here since...no more scary days."

\section{$\underline{\text { Discussion }}$}

Medication nonadherence is recognized as a common and important problem in HF but the reasons contributing to the behavior are inadequately understood. Previous investigators have described many of the intentional and unintentional factors contributing to nonadherence, but in this study qualitative data from a substantial sample of adults with chronic HF were used to explore the contribution of the Necessity-Concerns-Framework to our understanding of these factors. Ninety percent of the sample reported being nonadherent at least intermittently. For many (60\%), missing medication was unintentional and most commonly due to forgetfulness, but $27 \%$ reported intentional nonadherence. Four patterns of behavior were identified: 1) rarely nonadherent, 2) frequently nonadherent, 3) intentionally nonadherent, and 4) reformed nonadherent. Misperceptions about HF, beliefs, concerns, and contextual factors contributed to 
both intentional and unintentional medication nonadherence in these HF patients.

Others have also found that forgetting is the major reason for nonadherence in HF patients. Aggarwal et al reported that $60 \%$ of patients reported sometimes forgetting to take their medications. ${ }^{28}$ This finding suggests that interventions that augment prospective memory may decrease unintentional nonadherence. Prospective memory refers to the capacity to form, maintain, and execute an intention to perform a behavior at a particular point in the future. ${ }^{29}$ Intention (e.g., the intention to take a medication) initiates a process of monitoring for cues (e.g., a pill bottle), detecting cues, recalling the intention and then executing the behavior. That is, in patients who intend to take a medication, the conscious recollection of the planned event will stimulate pill taking. However, deficits in prospective memory are unlikely to factor into nonadherence if the patient has no intention of taking the pill (intentional nonadherence). This distinction illustrates the importance of understanding the reasons underlying medication nonadherence.

Knowledge, attitudes and beliefs influence illness perceptions and adherence. An important knowledge deficit in these patients was failure to recognize fatigue as a symptom of HF, so this symptom did not motivate medication adherence. This finding is similar to that of Horowitz et $\mathrm{al}^{30}$ who found that patients who misattributed their symptoms to aging were ineffective in managing their HF. These results suggest that the symptom of fatigue is vague to patients and warrants concerted attention during HF education sessions. Another knowledge deficit was in what to do if a medication dose is forgotten. Our finding that HF patients are uncertain about how to handle this situation is consistent with those of others who found that worrying and uncertainty were common in adults with diabetes experiencing insulin dosing problems. ${ }^{31}$ Handling a missed dose is clearly a situational skill that needs to be emphasized in teaching 
sessions.

An important belief with a powerful influence on adherence was the misconception that HF is not a threatening illness; individuals with this belief were likely to be intermittently nonadherent, at least until a hospitalization occurred. If $90 \%$ of patients admitted to some amount of nonadherence, a number consistent with early research in this area, ${ }^{2}$ it seems safe to assume that any HF patient admitted to the hospital unexpectedly should be engaged in a discussion of medication adherence. After hospitalization, some intentionally nonadherent patients became "reformed" and attended carefully to medication adherence. This finding supports the theoretical framework, which proposes that changes in cognitions produce changes in coping attempts. ${ }^{32}$ That is, as these patients became convinced that HF was life-threatening and medication could help, they became more adherent.

Concerns related to mood and regimen complexity interfered with adherence, as others have found. ${ }^{33-35}$ The concern that may be less appreciated is loss of control. Although perceived control is known to predict adherence to diet and exercise, less is known about perceived control in relation to medication adherence. Quine and colleagues ${ }^{36}$ identified perceived control as one of the leading predictors of medication nonadherence in a sample prescribed anti-hypertensive medications. In an earlier study, Piguet et $\mathrm{al}^{37}$ found that persons with chronic pain who were prescribed antidepressants reported effects on cognition, emotions, and personality, which induced feelings of dependence and loss of control. A loss of control led to ambivalence about taking the antidepressants and contributed to nonadherence. Exploring these concerns with patients may reveal issues for further discussion.

Contextual issues such as provider and automatic pharmacy renewal mistakes contributed in 
important ways to nonadherence. Fragmented care, medication cost, and side-effects were all factors, a finding similar to that of Laba et $\mathrm{al}^{38}$ who studied Australian adults prescribed medications for a diverse range of chronic conditions. They found that side effects and high cost were interpreted by patients as poor treatment decisions by providers, which contributed to nonadherence. Schuz and colleagues ${ }^{39}$ suggested that if older people with multiple illnesses are convinced that their medication serves their specific needs, they are likely to be adherent. But if doctors prescribe too many medications, those with unacceptable side-effect profiles, or expensive medications, patients are more likely to be nonadherent. Providers may not realize that patients judge the quality of the care they receive at least partially based on the medications prescribed. Our results illustrate that failure to discuss cost, side-effects, and the reason for prescribing a medication, risk nonadherence that is potentially preventable.

This study was strengthened by the use of qualitative secondary analysis techniques and the relatively large sample size. However, several limitations need to be acknowledged. In each of the four original studies, similar general questions were used to gather accounts of self-care and fidelity to the interview guide was monitored. Three of the four studies were descriptive but one was an intervention study testing motivational interviewing. ${ }^{40}$ In that study, these general questions were embedded within the intervention interview, but they were still the same questions. In a secondary data analysis such as this, the data rely on what was captured in the primary studies. Therefore, contradictory accounts of medication adherence that were not clarified at the time of the original interview required that discrepancies be resolved within the analysis process by determining the predominant theme in the transcribed data through content analysis. Another potential limitation is that we relied on subjective reports of medication adherence rather than objective measures. This led to subjective definitions of nonadherence. That is, we were not able to quantify the number of missed doses so nonadherence was defined 
based on participant reports.

\section{$\underline{\text { Implications for Practice }}$}

Implications include recognition that intentional and unintentional nonadherence are distinct phenomena, predicted by different factors, as others have noted. ${ }^{39,41}$ Thus, interventions need to target the issues underlying each individual's behavior. Considering the patterns identified, rarely nonadherent patients need only reinforcement and encouragement.

Those in the frequently nonadherent group have illness perceptions that are already appropriate (i.e., HF is a serious illness and medications are important), but medicines are routinely forgotten. They need interventions that address both knowledge (e.g., what a drug does) and action-planning (e.g., when to take it). Interventions for these two different memory problems differ. Patients who cannot remember what a drug is for need brief descriptions they can refer to while those who cannot remember to take a drug need memory triggers and a way to check whether or not they took it (e.g. a pillbox). Communication between providers at different settings (e.g. inpatients and outpatient settings) is essential when a patient is identified as frequently nonadherent. Education should include how to deal with missed doses. Most pharmacies have patient instructions for "What to do if I forget a dose or if I cannot recall if I took my medication" that should be provided routinely. Caregivers might be engaged to assist these patients to remember medications and should be provided with easy to understand information about the medications. In addition, role-playing exercises that facilitate problem solving and experiential learning may be useful. ${ }^{42}$ Identification of concerns (e.g., perceived loss of control) may reveal other targets for intervention.

The intentionally nonadherent patients need the most attention. Assessment of the symptom 
pattern may reveal a reason for nonadherence. Interventions should address knowledge, beliefs, and attitudes influencing illness perceptions using a strategy like motivational interviewing or another approach that addresses behavioral intention. The reformed nonadherent patients might be engaged to talk with the intentionally nonadherent patients about their experiences, as the reformed patients were intentionally nonadherent in the past. Further research is needed to confirm the behavioral patterns and to test the efficacy of these suggested interventions.

In summary, $90 \%$ of the sample reported being at least intermittently nonadherent. Most nonadherence is unintentional and due to forgetfulness, but a significant proportion of HF patients are intentionally nonadherent. Four patterns of behavior were described with specific interventions suggested for each pattern. Misconceptions about HF, beliefs, concerns, and contextual factors contribute to both intentional and unintentional nonadherence. The implication for health care professionals is to suspect intermittent nonadherence and address misconceptions, beliefs, and concerns as one way to improve adherence in this population of patients.

Acknowledgements: none

Conflicts of interest: none 


\section{REFERENCES}

1. Zhang Y, Baik SH. Race/Ethnicity, disability, and medication adherence among medicare beneficiaries with heart failure. Journal of general internal medicine. 2014;29:602-607.

2. Monane M, Bohn RL, Gurwitz JH, Glynn RJ, Avorn J. Noncompliance with congestive heart failure therapy in the elderly. Archives of internal medicine. 1994;154:433-437.

3. Osterberg L, Blaschke T. Adherence to medication. The New England journal of medicine. 2005;353:487-497.

4. Molloy GJ, Messerli-Burgy N, Hutton G, Wikman A, Perkins-Porras L, Steptoe A. Intentional and unintentional non-adherence to medications following an acute coronary syndrome: a longitudinal study. Journal of psychosomatic research. 2014;76:430-432.

5. Horne R. Compliance, adherence, and concordance: implications for asthma treatment. Chest. 2006;130:65S-72S.

6. Clifford S, Barber N, Horne R. Understanding different beliefs held by adherers, unintentional nonadherers, and intentional nonadherers: application of the Necessity-Concerns Framework. Journal of psychosomatic research. 2008;64:41-46.

7. Lewis LM. Factors associated with medication adherence in hypertensive blacks: a review of the literature. J Cardiovasc Nurs. 2012;27:208-219.

8. Turrise S. Illness Representations, Treatment Beliefs, Medication Adherence, and 30-Day Hospital Readmission in Adults With Chronic Heart Failure: A Prospective Correlational Study. J Cardiovasc Nurs. 2016;31:245-254.

9. Riegel B, Knafl GJ. Electronically Monitored Medication Adherence Predicts Hospitalization in Heart Failure Patients. Patient Preference and Adherence. 2014;8:1-13.

10. Lopert R, Shoemaker JS, Davidoff A, et al. Medication adherence and Medicare expenditure among beneficiaries with heart failure. Am J Manag Care. 2012;18:556-563.

11. Garavalia L, Garavalia B, Spertus JA, Decker C. Exploring patients' reasons for discontinuance of heart medications. J Cardiovasc Nurs. 2009;24:371-379.

12. Kim $E Y, H a n H R$, Jeong $S$, et al. Does knowledge matter?: intentional medication nonadherence among middle-aged Korean Americans with high blood pressure. J Cardiovasc Nurs. 2007;22:397-404.

13. Isherwood M, Serra M, Safirstein J, Shah N, Rosenthal M. Low-Dose Alteplase Infusion for the Treatment of Mechanical Aortic Valve Thrombosis: A Spotlight on the Importance of Medication Adherence. J Cardiovasc Nurs. 2016;31:262-266.

14. Unni EJ, Farris KB. Unintentional non-adherence and belief in medicines in older adults. Patient Educ Couns. 2011;83:265-268.

15. Chase JA, Bogener JL, Ruppar TM, Conn VS. The Effectiveness of Medication Adherence Interventions Among Patients With Coronary Artery Disease: A Meta-analysis. J Cardiovasc Nurs. 2016;31:357-366.

16. Ruppar TM. Randomized pilot study of a behavioral feedback intervention to improve medication adherence in older adults with hypertension. J Cardiovasc Nurs. 2010;25:470-479.

17. Leventhal H, Cameron L. Behavioral theories and the problem of compliance. Patient Educ Couns. 1987;10:117-138.

18. Leventhal $\mathrm{H}$, Weinman J, Leventhal EA, Phillips LA. Health Psychology: the Search for Pathways between Behavior and Health. Annual review of psychology. 2008;59:477-505.

19. Leventhal $H$, Safer MA, Panagis DM. The impact of communications on the self-regulation of health beliefs, decisions, and behavior. Health education quarterly. 1983;10:3-29.

20. Horne R, Weinman J. Patients' beliefs about prescribed medicines and their role in adherence to treatment in chronic physical illness. Journal of psychosomatic research. 1999;47:555-567.

21. Hinds $P$, Vogel $R$, Clarke-Steffen L. The possibilities and pitfalls of doing a secondary analysis of a qualitative data set. Qualitative Health Research. Qualitative Health Research. 1997;7:408-424. 
22. Long-Sutehall T, Sque M, Addington-Hall J. Secondary analysis of qualitative data: A valuable method for explorey sensitive issues with an elusive population. Journal of Research in Nursing. 2010;16:335-344.

23. Heaton J. Reworking qualitative data. London Sage Publications Limited; 2004.

24. Thorne S. Secondary Analysis in Qualiative Research: Issues and Implications. London: Sage Publications; 1994.

25. Noblit G, Hare R. Meta-ethnography:synthesising qualitative studies. London: Sage; 1988.

26. McCormick J, Rodney P, Varcoe C. Reinterpretations across studies: an approach to metaanalysis. Qual Health Res. 2003;13:933-944.

27. Byrne M, PhD. Data Analysis strategies for qualitative research. AORN Journal. 2001;74:904-905.

28. Aggarwal B, Pender A, Mosca L, Mochari-Greenberger H. Factors associated with medication adherence among heart failure patients and their caregivers. J Nurs Educ Pract. 2015;5:22-27.

29. Zogg JB, Woods SP, Sauceda JA, Wiebe JS, Simoni JM. The role of prospective memory in medication adherence: a review of an emerging literature. J Behav Med. 2012;35:47-62.

30. Horowitz $\mathrm{CR}$, Rein SB, Leventhal H. A story of maladies, misconceptions and mishaps: effective management of heart failure. Soc Sci Med. 2004;58:631-643.

31. Brod M, Pohlman B, Kongso JH. Insulin administration and the impacts of forgetting a dose. Patient. 2014;7:63-71.

32. Leventhal $\mathrm{H}$, Brissette I, Leventhal EA. The common-sense model of self-regulation of health and illness. In: Cameron LD, Leventhal $\mathrm{H}$, eds. The self-regulation of health and illness behaviour. Howard: Routledge; 2003:42-65.

33. Wu JR, Lennie TA, Dekker RL, Biddle MJ, Moser DK. Medication adherence, depressive symptoms, and cardiac event-free survival in patients with heart failure. J Card Fail. 2013;19:317-324.

34. Dickson VV, McCarthy MM, Katz SM. How do depressive symptoms influence self-care among an ethnic minority population with heart failure? Ethn Dis. 2013;23:22-28.

35. de Vries ST, Keers JC, Visser R, et al. Medication beliefs, treatment complexity, and nonadherence to different drug classes in patients with type 2 diabetes. Journal of psychosomatic research. 2014;76:134-138.

36. Quine L, Steadman L, Thompson S, Rutter DR. Adherence to anti-hypertensive medication: proposing and testing a conceptual model. Br J Health Psychol. 2012;17:202-219.

37. Piguet V, Cedraschi C, Dumont P, Desmeules J, Allaz AF, Dayer P. Patients' representations of antidepressants: a clue to nonadherence? Clin J Pain. 2007;23:669-675.

38. Laba TL, Lehnbom E, Brien JA, Jan S. Understanding if, how and why non-adherent decisions are made in an Australian community sample: a key to sustaining medication adherence in chronic disease? Res Social Adm Pharm. 2015;11:154-162.

39. Schuz B, Marx C, Wurm S, et al. Medication beliefs predict medication adherence in older adults with multiple illnesses. Journal of psychosomatic research. 2011;70:179-187.

40. Riegel B, Dickson VV, Hoke L, McMahon JP, Reis BF, Sayers S. A motivational counseling approach to improving heart failure self-care: mechanisms of effectiveness. J Cardiovasc Nurs. 2006;21:232-241.

41. Wroe AL. Intentional and unintentional nonadherence: a study of decision making. J Behav Med. 2002;25:355-372.

42. Chan ZC. Role-playing in the problem-based learning class. Nurse Educ Pract. 2012;12:21-27.

43. Dickson VV, Deatrick JA, Riegel B. A typology of heart failure self-care management in nonelders. Eur J Cardiovasc Nurs. 2008;7:171-181.

44. Riegel B, Dickson VV, Cameron J, et al. Symptom recognition in elders with heart failure. J Nurs Scholarsh. 2010;42:92-100.

45. Dickson VV, McCarthy MM, Howe A, Schipper J, Katz SM. Sociocultural influences on heart failure self-care among an ethnic minority black population. J Cardiovasc Nurs. 2013;28:111-118. 


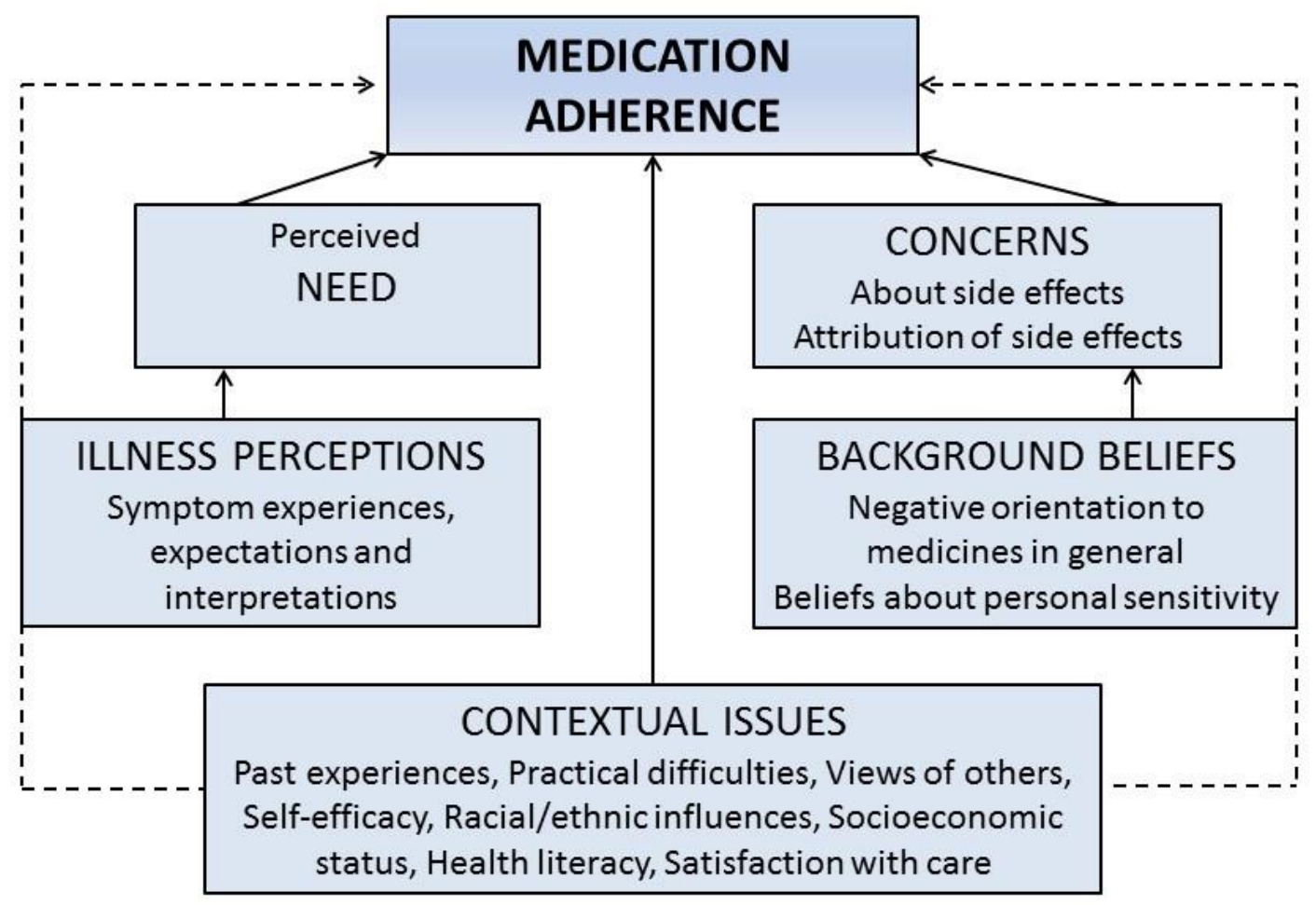

Figure Legend: The figure illustrates that illness perceptions influence patients' perceived need for a medication. If a drug is thought to be needed, medication adherence is likely. Individual beliefs and concerns greatly influence adherence. Even if the individual intends to adhere to the medication regimen, contextual factors such as finances may interfere with medication adherence.

Adapted from Horne ${ }^{6}$ with permission. 
Table 1: Description of studies used in this secondary analysis

\begin{tabular}{|c|c|c|}
\hline Study & Purpose & Sample Demographics \\
\hline Dickson et al ${ }^{43}$ & $\begin{array}{l}\text { To examine the contribution } \\
\text { of attitudes, self-efficacy, and } \\
\text { cognition to HF self-care } \\
\text { among non-elder patients } \\
\text { with HF }\end{array}$ & $\begin{array}{l}\mathrm{N}=4163 \% \text { male, } \\
68 \% \text { White; } \\
\text { Mean age } 49.2( \pm 10.51) \text { years; } \\
58.5 \% \text { NYHA III }\end{array}$ \\
\hline Riegel et al ${ }^{44}$ & $\begin{array}{l}\text { To explore age-related } \\
\text { differences in the ability to } \\
\text { perceive symptoms of HF }\end{array}$ & $\begin{array}{l}\mathrm{N}=29 ; 72 \% \text { Male; } 100 \% \text { born in } \\
\text { Australia of European or Asian } \\
\text { parentage; Mean age } 68.7( \pm 14.4) \\
\text { years; } 58.6 \% \text { NYHA II }\end{array}$ \\
\hline Riegel et al ${ }^{40}$ & $\begin{array}{l}\text { To assess the influence of } \\
\text { motivational interviewing on } \\
\text { self-care of adults with HF }\end{array}$ & $\begin{array}{l}\mathrm{N}=25 ; 64 \% \text { Male } \\
75 \% \text { White } \\
\text { Mean age } 63(11) \text { years; } \\
53 \% \text { NYHA II }\end{array}$ \\
\hline Dickson et al ${ }^{45}$ & $\begin{array}{l}\text { To describe socio-cultural } \\
\text { influences of HF self-care } \\
\text { among ethnic minority } \\
\text { population }\end{array}$ & $\begin{array}{l}\mathrm{N}=30,60 \% \text { male, } \\
100 \% \text { Black; } \\
\text { Mean age } 59.6( \pm 15.2) \text { years; } \\
67 \% \text { NYHA III }\end{array}$ \\
\hline
\end{tabular}


Table 2. Detailed description of the steps used in analysis

\begin{tabular}{|c|c|}
\hline Steps in Analysis & Example \\
\hline Sorting the primary data & $\begin{array}{l}\text { - } \text { Reviewed the qualitative data files and analysis files in } \\
\text { Atlas.ti (e.g., memos, code books, etc.) } \\
\text { - Identified data to exclude (i.e., no mention of medication) }\end{array}$ \\
\hline $\begin{array}{l}\text { Identify codes and themes } \\
\text { related to the new research } \\
\text { question }\end{array}$ & $\begin{array}{l}\text { Identified codes: medication, medicines, adherence, } \\
\text { nonadherence, self-care maintenance and their co- } \\
\text { occurring codes (e.g., symptoms, side-effects, cost). } \\
\text { - Developed new codes } \\
\text { - Categorized codes and themes as intentional (e.g., cost) or } \\
\text { unintentional (e.g., forgetfulness). }\end{array}$ \\
\hline $\begin{array}{l}\text { Analyze original data and } \\
\text { clarify interpretations }\end{array}$ & $\begin{array}{l}\text { Re-examined the original data, identifying intentional or } \\
\text { unintentional medication adherence. Additional coded } \\
\text { segments added to analysis. } \\
\text { - Explored coded data within the context of Necessity- } \\
\text { Concerns-Framework: For example, illness perceptions } \\
\text { (e.g., fatigue not linked to HF). } \\
\text { Identified patterns of medication nonadherence and the } \\
\text { contextual factors influencing adherence (e.g., social } \\
\text { support, finances) for each case (n=112). }\end{array}$ \\
\hline Interpretation & $\begin{array}{l}\text { - Synthesized the findings into } 4 \text { interconnected patterns of } \\
\text { behaviors: rarely nonadherent, frequently nonadherent, } \\
\text { intentionally nonadherent and reformed nonadherent; } \\
\text { describe the characteristics of each pattern. }\end{array}$ \\
\hline
\end{tabular}




\begin{tabular}{|l|l|}
\hline Translation of findings & $\begin{array}{l}\bullet \text { Reviewed these patterns within and across cases. } \\
\text { - Translated these findings within the context of Necessity- } \\
\text { Concerns-Framework. For example, symptom } \\
\text { interpretation influenced HF illness perceptions and } \\
\text { perceived need for medication. }\end{array}$ \\
\hline
\end{tabular}

$\mathrm{HF}=$ heart failure 
Table 3: Sociodemographic and clinical characteristics of the sample

\begin{tabular}{|c|c|}
\hline Demographic Characteristics & $\begin{array}{l}N=112 \\
M(S D)\end{array}$ \\
\hline Age & 58.9 (SD 15) \\
\hline & $\mathrm{N} / \%$ \\
\hline $\begin{array}{l}\text { Gender } \\
\text { - Male }\end{array}$ & $71(63 \%)$ \\
\hline $\begin{aligned} & \text { Race } \\
& \text { - } \text { White } \\
& \text { - } \text { Black } \\
& \text { - Asian }\end{aligned}$ & $\begin{array}{l}65(58 \%) \\
44(39 \%) \\
3(3 \%)\end{array}$ \\
\hline $\begin{array}{l}\text { Ethnicity } \\
\text { • Hispanic }\end{array}$ & $7(6 \%)$ \\
\hline $\begin{array}{l}\text { Marital Status (based on } \mathrm{n}=111 \text { ) } \\
\text { - } \text { Single, never married } \\
\text { - } \text { Married or cohabitating } \\
\text { - } \quad \text { Widowed/Divorced/Separated }\end{array}$ & $\begin{array}{l}41(37 \%) \\
48(43 \%) \\
22(20 \%)\end{array}$ \\
\hline 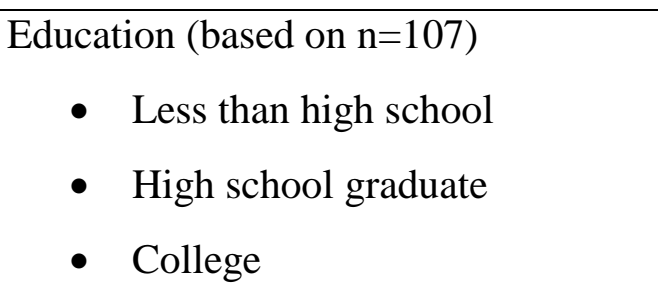 & $\begin{array}{l}20(18 \%) \\
40(36 \%) \\
51(46 \%)\end{array}$ \\
\hline Clinical Characteristics & $\mathbf{M}(\mathbf{S D})$ \\
\hline Years with HF (based on $n=111$ ) & 5.3 (SD 5.3) \\
\hline Ejection Fraction (based on $n=85$ ) & 32.7 (SD 16.2) \\
\hline & $\mathrm{N} / \%$ \\
\hline $\begin{array}{l}\text { NYHA Class (based on } \mathrm{n}=111 \text { ) } \\
\text { Class II } \\
\text { Class III } \\
\text { Class IV }\end{array}$ & $\begin{array}{l}45(41 \%) \\
61(55 \%) \\
5(5 \%)\end{array}$ \\
\hline Type of HF (based on $n=81$ ) & \\
\hline
\end{tabular}




\begin{tabular}{|l|c|}
\hline - Systolic/Mixed & $105(94 \%)$ \\
- Diastolic & $7(6 \%)$ \\
\hline
\end{tabular}

SD: standard deviation; HF: heart failure; NYHA: New York Heart Association 